\title{
Caderninhos da Déborah: a história do livro didático passa por aqui
}

Em agosto de 1994, a editora Ibep venceu a concorrência da Fundação de Assistência do Estudante (FAE) para distribuição de 11,5 milhões de livros didáticos a seis milhões de crianças. Dois de seus livros - Viajando com as Palavras $e$ Viajando com os Números, de português e matemática - foram escritos pela professora Déborah Pádua Mello Neves, autora do Ibep desde 1970, com mais de cem títulos publicados. Professora aposentada do magistério, três filhos, nove netos e quatro bisnetos, iniciou a carreira de autora no importante periodo de transição da educação $e$ do livro didático brasileiro. Época de reformas educacionais e da expansão da escola pública, incipiente até então, de consolidação da impressão de textos escolares no Brasil e de renovação de idéias e procedimentos para atender às modificações de currículos e programas, que representam o progresso considerável sobre o padrão de livro didático vigente até a Primeira Guerra Mundial. No dia em que completou 88 anos de vida, ela nos concedeu este depoimento, e acabava de receber em sua casa a mais nova coleção de sua autoria, Os Cadernos de Caligrafia, da Coleção Novo - Eu gosto, outro sucesso da editora onde trabalha até hoje.

Por Consuelo Ivo

Sempre vivi em um ambiente de educação. Nasci em Maracaí (SP) e com dois anos de idade minha família se mudou para Laranjal Paulista, onde estudei até a $4^{\text {a }}$ série. Minha mãe lecionava em uma fazenda e, como eu era a mais velha de quatro filhos até aquela época (depois vieram mais dois), ia com ela para a escola. Ficava sentadinha num banco, ao lado da mesa dela, com papel e lápis para rabiscar. Ali também eu debruçava na mesa, descansava, dormia.

Um dia minha mãe chamou um aluno para ler e ele ficou todo atrapalhado. Eu havia observado que os alunos, quando sabiam, levantavam a mão, se prontificando para a tarefa. Levantei a mão e a mamãe, por graça, disse: "Leia, Déborah". E li tudo: estava alfabetizada com cinco anos de idade. Naquele tempo, a idade mínima para entrar na escola era de sete anos. Assim, tive de esperar dois anos para ser matriculada. Mais tarde, enfrentei o mesmo problema para a admissão no Curso Normal. Novo ciclo, nova cidade.

Mudamos para Bauru, onde fiz o curso normal no Colégio Guedes de Azevedo. Formei-me em 1936 - muito nova -, e já comecei a trabalhar como professora. Primeiro como substituta num grupo escolar, depois fui para uma escola municipal rural. Naquele tempo havia o concurso para o Estado e o que contava pontos eram as notas. Como alcançei notas muito boas, fui chamada. Mas os

1. PFROMM-NETTO, Samuel apud NEVES, Edna Roséle da Conceição Neves. Uma trajetória pela história da atividade editorial brasileira: livro didático de matemática, autores e editoras. 2005. Dissertação de Mestrado. Pontifícia Universidade Católica de São Paulo, São Paulo, 2005. p. 120. 
lugares eram difíceis ... Era no litoral, eu tinha que pegar barco etc., e meus pais acabaram não concordando. Mais tarde fiz novo concurso e comecei a lecionar no Estado.

Dei aulas em um núcleo da colônia japonesa com 40 alunos, 39 deles japoneses. O ensino de língua japonesa no Brasil começou com a vinda dos imigrantes, em 1908. Eles construíram muitas salas de aula no Estado de São Paulo. Compareciam professores do Estado, do município etc. Eu lecionava na parte da manhã e, à tarde, os alunos tinham aula da língua materna com um professor japonês. Com a Segunda Guerra Mundial, o Brasil se aliou aos países que combatiam o eixo formado por Japão, Itália e Alemanha. A situação,

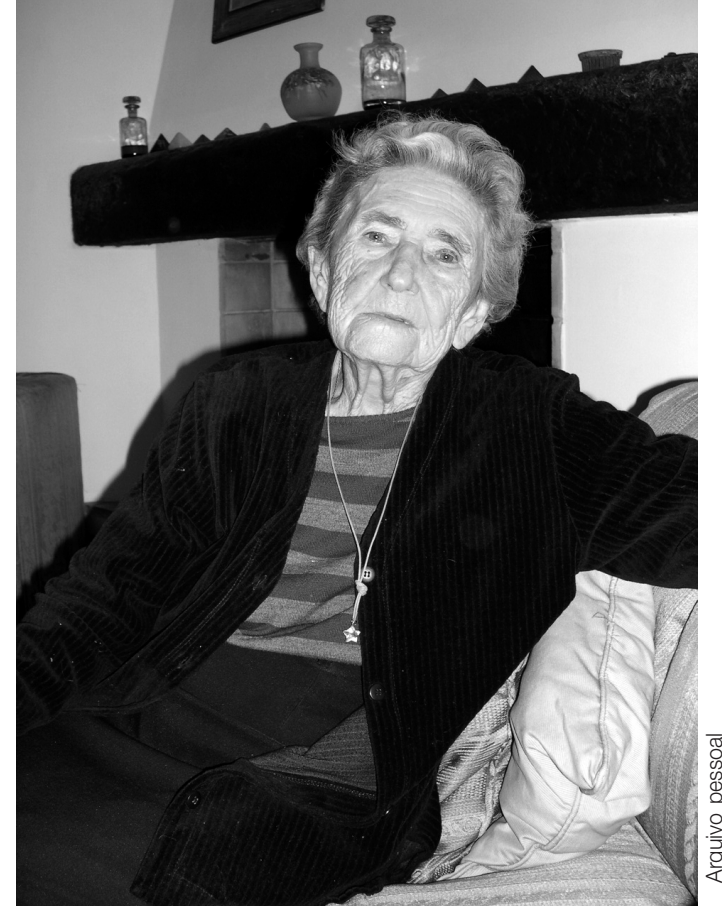

Professora Déborah Pádua Mello Neves, autora do Ibep desde 1970, com mais de cem títulos publicados. naturalmente, se tornou crítica para os imigrantes, que sofreram retaliações. Em nome da segurança nacional, os japoneses que moravam numa faixa de até 50 quilômetros do litoral brasileiro foram obrigados a se retirar para o interior do país. Os alunos menores de 10 anos foram impedidos de continuar os estudos nas escolas japonesas. A decisão partiu do governo de São Paulo, que vinha adotando medidas nacionalistas mais severas desde 1933. O governo Getúlio Vargas, no final da mesma década, baixou um pacote de medidas xenófobas, proibindo o ensino de língua estrangeira no país. A imprensa de língua estrangeira começou a ser censurada e os estrangeiros foram proibidos de exercer qualquer atividade de natureza política As escolas foram fechadas e confiscadas.

\section{CADERNINHOS}

Nesse meio tempo, fui lecionar na cidade de Paulistânia, não muito longe de Bauru, onde fiquei por três anos. Dava aulas para alunos de $3^{\mathrm{a}}$ série, pois não existia o que eles chamavam na época de grupo escolar. Só no final daquele ano que a escola introduziu a $4^{\mathrm{a}}$ série. Tínhamos salas com alunos de 11 a 17 anos. O Brasil começava a oferecer mais escolas públicas e muitas pessoas só puderam freqüentá-la tardiamente.

Lecionei também na cidade de Piratininga, também na zona rural, antes de ser transferida para Bauru, que acabara de ganhar vários grupos escolares, além das duas escolas existentes até então. Nessa época minha mãe era professora numa escola do centro da cidade, enquanto eu trabalhava numa vila. 
Aos 23 anos, casei-me com um farmacêutico que era funcionário público. Fui lecionar na escola anexa ao Instituto de Educação Ernesto Monte. Nessa época os alunos do instituto precisavam de um curso primário para fazer o estágio de prática de ensino. Fui escolhida para ser a primeira professora desse curso primário. Iniciei com alunos da $3^{\mathrm{a}}$ série e depois fiquei com os da $4^{\mathrm{a}}$ série até me aposentar. Passei também a oferecer curso preparatório para o exame de admissão ao ginásio - muito rigoroso -, que vigorou até 1970. Muitos alunos meus da 4 $4^{\text {a }}$ série estudaram comigo nesse preparatório.

Eu encontrava muita dificuldade para que eles aprendessem Geografia, História e Ciências, porque enfrentava problemas com a lentidão de alguns para copiar a matéria do quadro, ou com os muitos erros cometidos quando eu fazia o ditado. Ia passando de carteira em carteira e notava os problemas. Para ajudá-los, resolvi produzir os meus primeiros livros didáticos, chamados de Caderninhos.

Como ficava muito cara a impressão, fui conversar com o pai de um aluno que era meu vizinho e trabalhava com gráfica. A solução que ele me propôs foi fazer uma tiragem mínima de trezentos Caderninhos para baratear o custo. Mas eu ia utilizar apenas quarenta! O que fazer com o restante? Com muita dificuldade financeira, fiquei em dúvida sobre editá-los ou não. Mas eu disse: "Hoje é o meu dia 'D', dia de decisão”. E resolvi publicar. Vendia para os alunos do preparatório, bem baratinho. No Colégio São José, uma freira viu uma de minhas alunas do preparatório com o Caderninho e gostou muito dele; quis saber quem havia preparado aquele material e perguntou se existia algum à venda. Assim vendi mais quarenta! Outras duas colegas, mães de alunos meus do preparatório,

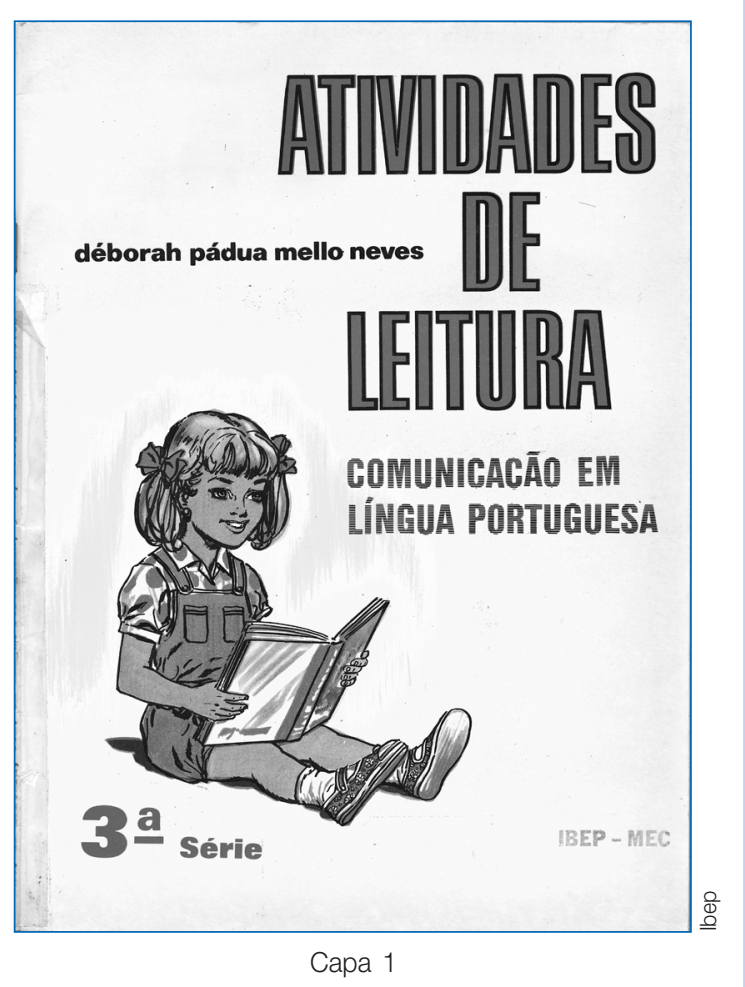
também conheceram o material e o adotaram. Os restantes foram sendo vendidos, e assim eu me tornei autora.

Como disse, o exame de admissão ao ginásio era muito difícil, uma espécie mesmo de vestibular. Felizmente, meu curso era bem considerado, pois eu apertava os alunos, como se dizia na época sobre os professores exigentes. Os questionários do exame de admissão eram enviados de São Paulo, e o aluno que não estivesse preparado não conseguia passar. Havia muitas reprovações nessa época. Depois do sucesso dessa primeira edição e já com todos os Cadernos vendidos, minha mãe se lembrou de que nossa família era muito amiga do João Batista Martins 
2. Ancorada nos movimentos sociais desde a década de 1970, a Caixa Escolar passou a ter maior importância a partir de meados da década de 1990, quando o MEC começou a transferir recursos financeiros diretamente para as unidades escolares, de acordo com o princípio da escola autônoma, estabelecido na Lei de Diretrizes e Bases da Educação de 1996. Outras estruturas de gestão colegiada que podem atuar no lugar ou em conjunto com a Caixa Escolar são a Associação de Pais e Mestres (APM), - Colegiado Escolar e o Conselho de Escola. (N.E.)
Coube, dono da Tilibra. Meus pais haviam convivido com ele em Botucatu, na juventude. Fomos visitá-lo e ele concordou em imprimir os cadernos. Além disso, iniciou uma propaganda do meu trabalho em outras escolas e cidades.

As professoras que eram minhas colegas começaram a pedir que eu fizesse também cadernos para as outras séries. Acabei editando os livros de Geografia, História e Ciências para segunda e terceira séries. Depois vieram os de Português e de Matemática. Terminei redigindo a coleção toda! Inicialmente, realizava o trabalho intuitivamente, além de comprar material para me atualizar, estudar e preparar os questionários. Mandava vir livros de São Paulo e, principalmente, do Rio de Janeiro. Fui adaptando os livros à maneira que o ensino era modificado. $\mathrm{O}$ primeiro caderninho que fiz era só de perguntas e respostas, não tinha uma única ilustração. Pouco depois comecei a inserir ilustrações que recortava de jornais, revistas, e o pessoal da Tilibra preparava a arte. Às vezes falava diretamente com o ilustrador e pedia algo mais objetivo. Fiquei dezenove anos editando meus livros na Tilibra. Eles possuíam representantes no Brasil todo e vendiam muito.

\section{AUTORA BEST-SELLER}

Entretanto, num momento difícil, tive que mudar de editora. Meu marido estava doente e precisamos procurar tratamento em São Paulo. Um primo dele foi visitá-lo e levou consigo um senhor que era presidente da Caixa Escolar ${ }^{2}$, órgão do governo para ajudar alunos carentes. Nesse encontro no hospital ele me falou da dificuldade em encontrar meus livros e perguntou se eu não gostaria de morar em São Paulo. Disse-lhe que sim, se fosse possível, mas também que essa idéia nunca havia passado pela minha cabeça.

Soube depois que ele estivera no Ibep - Instituto Brasileiro de Edições Pedagógicas, que mais tarde, em 1980, iria adquirir a Companhia Editora Nacional, fundada em 1925 por Monteiro Lobato, formando um dos maiores grupos editoriais do país, com capital $100 \%$ brasileiro. Foi ele quem falou sobre o meu trabalho e a possibilidade de eu me transferir para São Paulo. Eles me telefonaram e solicitaram a minha presença lá. Passei três dias com eles, saindo ao final com um contrato, assinado em 30 de setembro de 1977. Completei 37 anos de Ibep!

Com a editora iniciei uma nova fase como autora, o que foi uma maravilha. Nesse meio tempo meu marido faleceu e acabei vindo para São Paulo de vez, com meus três filhos. Os editores eram excelentes, orientavam muito bem a todos nós. Fazíamos livros com eles ao nosso lado; era muito prazerosa a convivência. Eu fui uma das primeiras autoras de livros para o ensino primário; depois é que vieram outros autores para a editora, como as professoras Gilda de Guimarães Piedade, Edna Lapa, Eunice Iost, Ruth Araújo. A editora formou o seu time inicial de autores com livros de alfabetização e de $1^{\underline{a}}$ a $8^{\text {a }}$ séries. Do parque gráfico, na rua Bresser, saíram os primeiros livros editados pela empresa, como O Curso Moderno de Admissão, seguido da cartilha A Hora Alegre, além de obras de Português, Matemática e Estudos Sociais. 


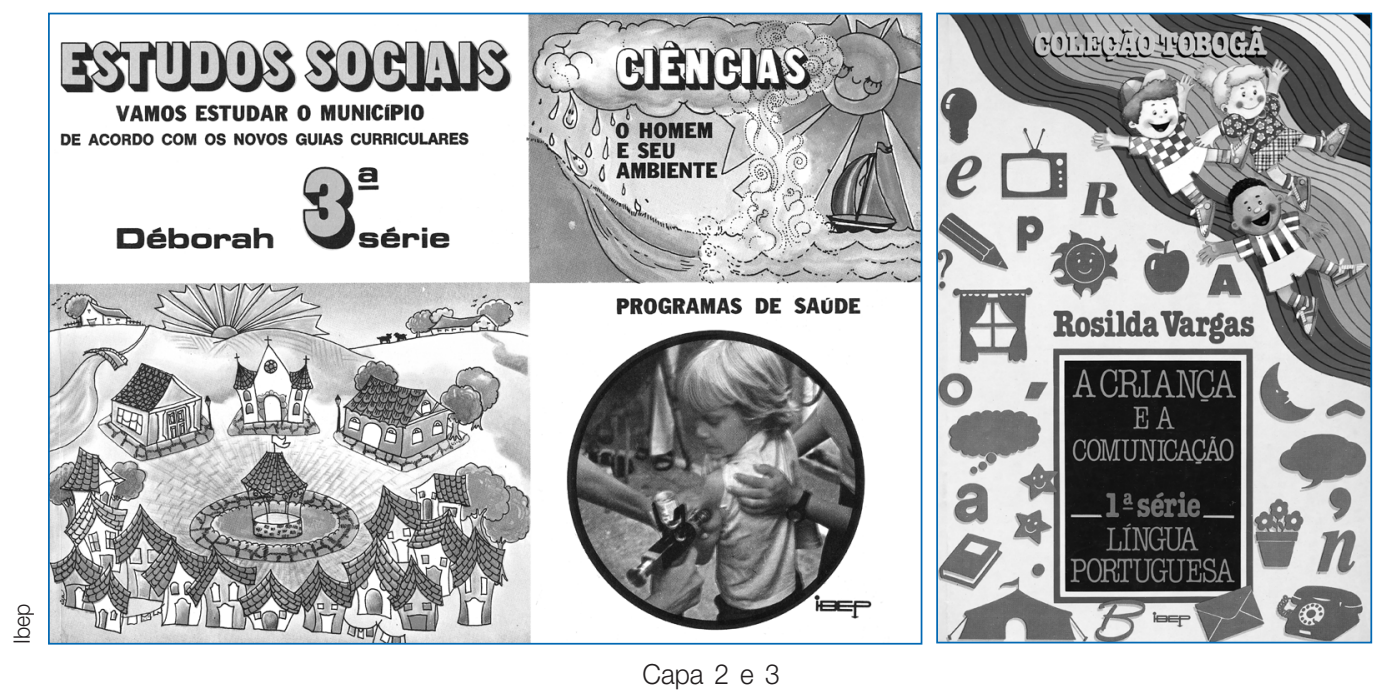

Ao longo da carreira, recebi poucas críticas negativas ao meu trabalho. Recebia muitas cartas na editora, geralmente elogiosas, ou com sugestões. Durante os primeiros dez anos assinava os livros com meu nome. Seguindo uma tendência na época, passei a usar também pseudônimos. Assinei como Yolanda Marques, entre outros, e os livros continuaram a ser muito bem recebidos.
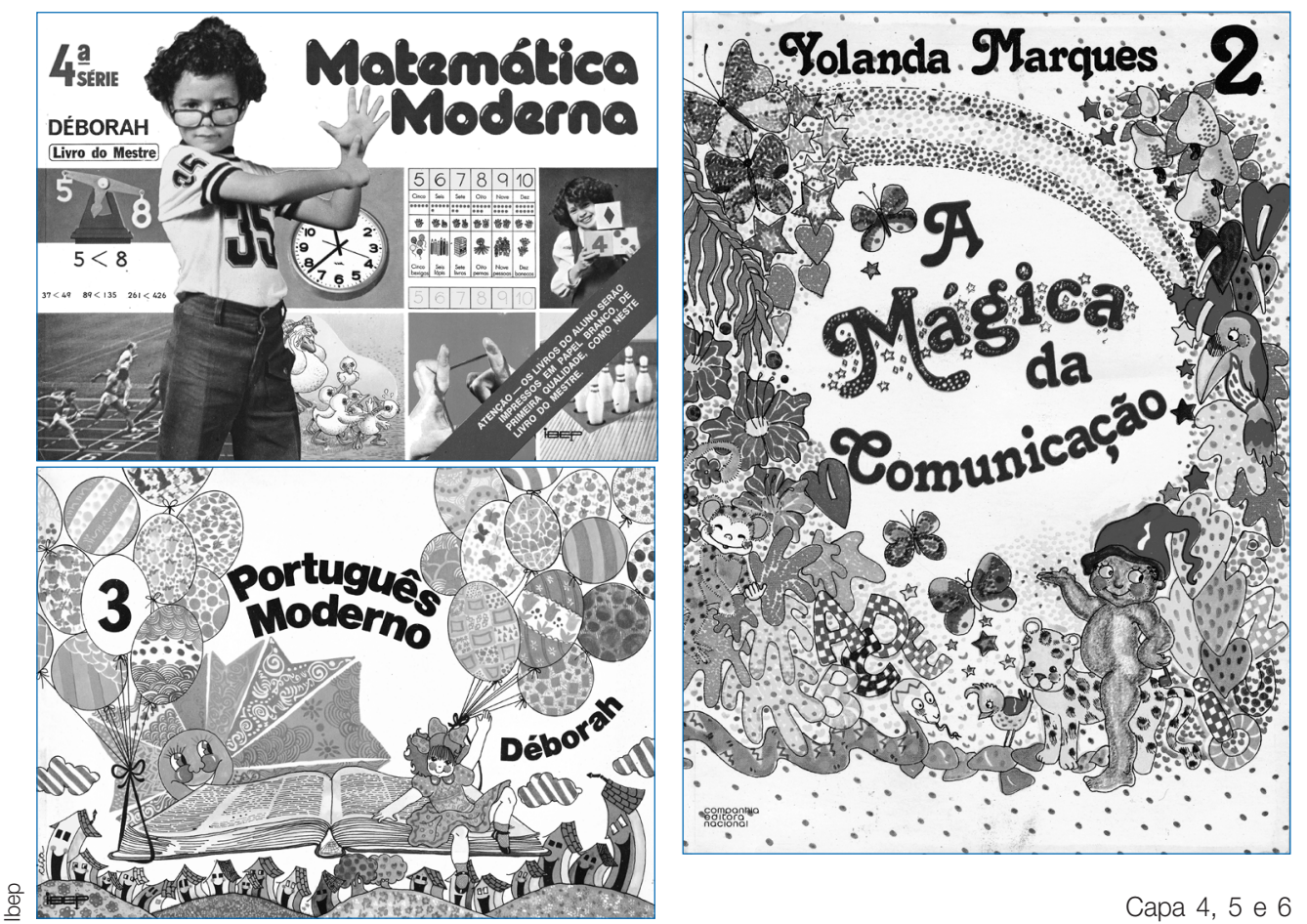

\section{PRÁTICA E VERSATILIDADE}

Em agosto de 1994, a editora Ibep venceu a concorrência da então Fundação de Assistência do Estudante (FAE) ${ }^{3}$ para distribuição de 11,5 milhões de livros didáticos a seis milhões de crianças. Dois dos livros - Viajando com as

3. Atual Fundo Nacional de Desenvolvimento da Educação. O governo federal executa três programas voltados ao livro didático: o Programa Nacional do Livro Didático (PNLD), o Ensino Médio (PNLEM) e o Alfabetização de Jovens e Adultos (PNLA). Em 2007, o orçamento total dos três programas foi de $\mathrm{R} \$ 850$ milhões, sendo R\$ 620 milhões para o PNLD, R\$ 220 milhões para o PNLEM e R\$ 10 milhões para o PNLA. (N.E.) 
Palavras e Viajando com os Números, de Português e Matemática - eram meus. Naquele ano, tornei-me uma das escritoras que mais vendeu livros no Brasil, superando muitos best-sellers.

Em 2006 fui chamada pelo chefe de editorial do Ibep, que me pediu para fazer um livro de caligrafia. Eu disse que não seria possível. "Sempre utilizei caligrafia quando era necessário nas escolas, mas agora não tenho prática", argumentei. Mas ele insistiu, dizendo que eu tinha, sim, prática e que deveria criar o livro. Forneceu-me alguns modelos e dali a algum tempo, quanto retornei com o material pronto, ele disse que tinha ficado melhor do que o esperado e me mandou fazer o restante da coleção. Criei um sistema diferente, introduzindo jogos, textos etc. Os livros procuram se comunicar com as crianças de maneira atraente e lúdica. Ao mesmo tempo em que ensinam a escrever com boa letra e sem erros de ortografia, incentivam a leitura e a produção de textos. Enquanto desenvolvem essas habilidades, as crianças aprendem a se comunicar com seus colegas. Os quatro volumes têm crescente gradação de dificuldade, o que estimula o desenvolvimento da criança. Podem ser usados do primeiro ao quinto ano, de acordo com as necessidades de aprimoramento dos estudantes.

Certamente, acompanhei a evolução da educação e é muito triste saber que o País tem tantas dificuldades para superar. Sempre adorei lecionar e escrever. Encontro com meus ex-alunos até hoje e é sempre uma alegria. Acho que fiz o que sabia e podia por eles, e depois um pouco mais, com a dedicação nestes quase sessenta anos voltados ao livro didático. Sempre retratei os fatos da atualidade em meus trabalhos, principalmente nos livros de Português, com textos regionais, literatura de cordel, enfim, sempre procuramos oferecer mais qualidade no trabalho. Elaborei no ano de 2007 uma última coleção, pois quero descansar um pouco. São exercícios de Matemática, Português, Geografia, História e Ciências. Muitos exercícios!

Resumo: Neste Depoimento, a professora aposentada do magistério Déborah Pádua Mello Neves, autora de livros didáticos, relata como se tornou uma das escritoras que mais vendeu livros no Brasil. Iniciou suas atividades no importante período de transição da educação e do livro didático brasileiro. Época de reformas educacionais e da expansão da escola pública, incipiente até então, de consolidação da impressão de textos escolares no Brasil e de renovação de idéias e procedimentos para atender às modificações de currículos e programas que representam o progresso considerável sobre o padrão de livro didático vigente até a Primeira Guerra Mundial.

Palavras-chave: magistério, livro didático, história da educação, linguagem.
Abstract: In this testimony, the retired teacher of teaching Déborah Pádua Mello Neves, author of textbooks, tells us how she became one of the authors that have sold more books in Brazil. She initiated her activities in an important period of transition in Brazilian education and textbook: time of educational reforms and expansion of an incipient public school, of the school texts printing consolidation, of ideas and procedures renewal to attend to curriculum and program changes that represented a remarkable increase in the standard textbook that existed until the First World War.

Keywords: teaching, textbook, history of education, language. 